\title{
Reparación integral para las comunidades indígenas afectadas por el conflicto armado interno ${ }^{1}$
}

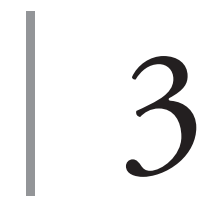

\author{
https://doi.org/10.21830/9789585241480.03
}

Paola Alexandra Sierra-Zamora
Escuela Militar de Cadetes “General José María Córdova”
Hans Nicolaysen Sánchez
Universidad Católica de Colombia
Manuel Bermúdez-Tapia
Universidad Privada San Juan Bautista
Fredy Galindo García
Escuela de Derechos Humanos, DIH y Asuntos Jurídicos

1 Este capítulo hace parte de los resultados del proyecto de investigación "Desafíos contemporáneos para la protección de derechos humanos en escenarios de posconflicto desde enfoques interdisciplinarios - FASE II" del Grupo de Investigación Persona, Instituciones y Exigencias de Justicia, del Centro de Investigaciones Sociojurídicas, Facultad de Derecho, de la Universidad Católica de Colombia, registrado con el código COL0120899 de Minciencias. También contó con la colaboración de los siguientes proyectos de investigación: "La legitimidad de las Fuerzas Militares en la geopolítica nacional e internacional de Colombia" del Grupo de Investigación en Ciencias Militares, de la Escuela Militar de Cadetes “General José María Córdova” (ESMIC), registrado con el código COL0082556 de Minciencias; "Análisis del perfil criminológico de adolescentes infractores para evaluar tasas de reincidencia delictiva que afecte la seguridad ciudadana", aprobado por Resolución Vicerrectoral No 058-2018-VRIUPSJB de la Universidad Privada San Juan Bautista, Perú; y "Modelo de enseńanza-aprendizaje en (DDHH) Derechos Humanos y (DIH) Derecho Internacional Humanitario en el Ejército Nacional de Colombia a través del juego y la simulación” del Grupo de Investigación del Centro de Misiones Internacionales y Acción Integral (CEMAI). Los puntos de vista y los resultados de este capítulo pertenecen a los autores y no reflejan necesariamente los de las instituciones participantes.

2 Abogada de la Universidad Católica de Colombia. Magíster en Derechos Humanos, Democracia y Justicia Internacional por la Universitat de València, España. PhD (c) del Programa de Derechos Humanos, Democracia y Justicia Internacional por la Universitat de València, Espańa. Investigadora del Grupo de Investigación en Ciencias Militares de la Escuela Militar de Cadetes "General José María Córdova”. Orcid: https:// orcid.org/0000-0002-3146-7418. Contacto: paola.sierra@esmic.edu.co

3 Estudiante de la Facultad de Derecho de la Universidad Católica de Colombia y miembro del semillero de investigación "Observatorio de justicia constitucional de derechos humanos", vinculado al Grupo de Investigación Persona, Instituciones y Exigencias de Justicia, de la Universidad Católica de Colombia.

4 Abogado (magna cum laude) de la Pontificia Universidad Católica del Perú. Profesor-investigador de la Universidad Privada San Juan Bautista y profesor de la Facultad de Derecho de la Universidad Nacional Mayor de San Marcos. Consultor en temas de reforma del sistema de justicia en el Perú para el Banco Mundial, el Congreso de la República, el Poder Judicial y la Academia de la Magistratura. Orcid: https://orcid.org/0000-00031576-9464. Contacto: manuel.bermudez@upsjb.edu.pe

5 Teniente Coronel del Ejército Nacional de Colombia. Abogado de la Universidad Militar Nueva Granada. Director de la Escuela de Derechos Humanos, DIH y Asuntos Jurídicos del Ejército de Colombia. Orcid: https://orcid.org/0000-0001-7361-5629. Contacto: fredy.galindo@buzonejercito.mil.co 


\section{Resumen}

La reparación integral para las comunidades indígenas en el posacuerdo colombiano tiene como fin restaurar los daños ocasionados a los derechos humanos de estas comunidades mediante diferentes mecanismos que procuran facilitar el cumplimiento de los aspectos tratados en el Acuerdo Final para la Paz.

En este capítulo se analiza el nivel de vulneración de los derechos humanos de estas comunidades a consecuencia del conflicto armado interno en Colombia, con el fin de identificar cómo atenderlas en forma específica y validar el proceso de justicia transicional desarrollado a partir del acuerdo de paz.

Sobre la base de la identificación del daño en los derechos humanos a los integrantes de las comunidades indígenas, surge la necesidad de establecer un reconocimiento especial a este grupo en situación de vulnerabilidad y en condiciones negativas en términos históricos, en el contexto del pacto por la reparación integral de víctimas.

Palabras clave: comunidades indígenas; derechos humanos; justicia y reparación; poblaciones vulnerables; posacuerdo

\section{Introducción}

Colombia es uno de los países con mayor número de desplazados internos (D’Angelo, 2017), fenómeno que implica un sinnúmero de vulneraciones y violaciones a los derechos humanos de los pobladores afectados (Garay Acevedo y Pérez Guecha, 2018; Sierra-Zamora, 2018). Tal situación permite identificar varios niveles de vulnerabilidades, de acuerdo con Bermúdez-Tapia (2011, p. 36):

a. Las víctimas directas del conflicto armado interno, quienes se encuentran entre las fuerzas del Estado y los grupos insurgentes.

b. La población en general del país, quienes son víctimas indirectas porque el nivel de dańo se percibe en el ámbito estructural tanto en lo social, en lo cultural, en lo político como en lo económico.

c. Los niños, niñas y adolescentes (en adelante NNA) quienes son víctimas invisibles en un contexto en el cual se ven afectados porque sus familias pueden disgregarse, pueden verse limitados por división interna o por una situación de muerte a manos de las partes en conflicto armado.

d. Las personas que han perdido familiares en el conflicto armado interno, los cuales asumen una condición de vida negativa especialmente en lo psicológico. 
e. Los sectores rurales, de aislamiento geográfico y expuestos a las acciones de los grupos insurgentes, principalmente porque son víctimas que no cuentan con un nivel de atención efectivo e inmediato por parte del Estado.

En este punto, es necesario mencionar que las poblaciones indígenas han sido "desplazadas" de modo diferente, en función de la naturaleza de los hechos del conflicto armado interno; en algunos casos el nivel de desplazamiento ha sido severo y en otros casos, las poblaciones indígenas han estado muy próximas a zonas donde se desarrollaba el conflicto armado.

Sin embargo, sobre la base de la realidad nacional, los desplazados en Colombia, en su gran mayoría, son personas que pertenecen a comunidades étnicas como los indígenas o los afrocolombianos (Bello, 2003), problemática que arraiga múltiples discriminaciones y exclusiones en los marcos políticos, económicos y socioculturales del Estado. En muchos casos, las comunidades que son y fueron víctimas del conflicto interno armado son comunidades ignoradas por el Estado (Cubides-Cárdenas y Sierra-Zamora, 2018) que han logrado sobrevivir con sus propios recursos y estrategias.

Ahora bien, los pueblos indígenas hace más de treinta años se constituyeron como sujetos importantes para el desarrollo del país, por lo cual es necesario abarcar un ordenamiento territorial incluido en la Constitución Política de Colombia de 1991 (Villa y Houghton, 2005). Esto demuestra una representación política en cuanto a la garantía de territorios y locaciones que son otorgadas a las comunidades indígenas.

El problema yace en la necesidad de comprender las difíciles situaciones a las que son sometidas las comunidades indígenas, empezando por el desplazamiento forzado generado por acciones violentas de grupos armados al margen de la ley o por terratenientes (Ibáñez y Querubín, 2004) que buscan territorios estratégicos y recónditos para establecer bases militares, cultivos ilícitos o apropiarse de las tierras. Se entiende, por tanto, la compleja lucha en favor de los derechos colectivos indígenas y el surgimiento de movimientos en busca de ellos a partir de la segunda mitad del siglo XX (Sevilla, 2007).

En este sentido, el presente capítulo se desarrolla por medio de la metodología de investigación cualitativa propositiva, la cual consiste en la revisión 
literaria con eje y enfoque de tipo doctrinal, a partir de la pregunta siguiente: ¿Cómo se han determinado las acciones del Estado para generar un procedimiento que desarrolle una reparación integral frente a las violaciones de derechos humanos en las comunidades indígenas de Colombia? Este capítulo tiene por objeto evidenciar las diferentes vulneraciones a los derechos humanos (en adelante, DD. HH.) de las comunidades indígenas en Colombia, además de exponer las actuaciones que el Estado colombiano ha propuesto en el Acuerdo Final para la Paz con fines de la reparación integral de víctimas.

Para desarrollar el capítulo, es necesario entender cuatro ejes temáticos. Inicialmente se procura reconocer a la población indígena para tener un referente de las comunidades de las que se va a tratar. En la segunda etapa se evalúan los diferentes modos en que son vulnerados los derechos humanos de las comunidades indígenas. En una tercera etapa, se trata el Acuerdo Final para la Paz y las posiciones que las comunidades indígenas ocuparon en este. En una cuarta etapa, se interpreta la manera en la que la reparación integral de víctimas planteada en el posacuerdo del conflicto colombiano entra en contacto real con las comunidades indígenas.

\section{Población indígena en Colombia}

La población indígena ha sido reconocida como una entidad territorial desde la actualización de la Constitución de 1991 (Laurent, 1997), y a efectos de poder evaluar su volumen poblacional ha sido necesario ejecutar diferentes censos. Sin embargo, surge un gran inconveniente para evaluar correctamente a este grupo poblacional, en especial debido a factores socioculturales y estructurales, por ejemplo, el proceso de mestizaje, el proceso de movilización en cuanto al ámbito geográfico, la dispersión demográfica, el atavismo respecto de la identificación como persona indígena ante el proceso de exclusión social al cual usualmente es sometida esta comunidad (Bermúdez-Tapia, 2017, p. 71).

Complementariamente, Bermúdez-Tapia (2017, p. 69) afirma que las poblaciones indígenas han sido diferenciadas con base en una serie de denominaciones que ha provocado situaciones de indefensión, en especial, porque 
el Estado no ha considerado el desarrollo de sus derechos, por ello surgen una serie de situaciones que deben relacionarse en forma complementaria, como también en forma autonómica:

a. Los derechos de las poblaciones indígenas implican una condición tripartita de situaciones, por cuanto el indígena es sujeto de derechos, la comunidad también y cualquier sujeto puede actuar en defensa de los intereses y derechos de una comunidad indígena si se encuentra legitimado para ello. En esencia, este contexto permite detallar que la mayor parte de la defensa de los derechos indígenas ha sido evaluada a nivel individual, por las complicaciones materiales que surgen en la tutela de derechos colectivos o comunitarios o de intereses difusos, por ejemplo, los vinculados al medioambiente.

b. Las comunidades indígenas, en forma sustancial, son diferentes de las comunidades campesinas, las cuales pueden ser producto de situaciones de coloniaje, mestizaje o de dedicación económica a la agricultura. Sin embargo, es posible identificar que una comunidad indígena puede ser una comunidad campesina, pero no al revés.

c. El contexto de la tutela de derechos colectivos o comunitarios puede provocar situaciones legales complejas, tanto a nivel nacional como a nivel internacional, prueba de ello es que el Sistema Interamericano de Derechos Humanos ha desarrollado una jurisprudencia aplicable a poblaciones indígenas en Paraguay, Ecuador y Perú, entre otros países.

d. Las poblaciones indígenas van perdiendo el carácter especial que implica una condición étnica particular, por motivos de mestizaje y asimilación cultural. Esto incide negativamente en su propio desarrollo, pues atenta de manera directa contra el patrimonio histórico cultural de la nación, porque en esencia ese valor es del país y no constituye una referencia excluyente de las poblaciones indígenas.

Tomando en cuenta estas referencias, se considera que la terminología debe emplearse en forma conjunta, pero con una perspectiva especial, porque también se debe vincular el contexto normativo internacional.

Coloquialmente, la población nacional ha podido identificar las principales características de esta población, pero el sistema de medición poblacional del Instituto Nacional de Salud entre 1993 y 1994 evidencia que se ha ubicado a los grupos étnicos más numerosos del país, a través de un proceso de identificación por selección de asentamientos. Para ello se tomaron en cuenta factores como la accesibilidad, los problemas de orden público y el interés y la acepta- 
ción de la encuesta por parte de las autoridades indígenas (Pińeros-Petersen y Ruiz-Salguero, 1998).

Dicha encuesta plantea un programa que permite reconocer de forma certera la cantidad de indígenas que habitan en la nación. Este factor permite constituir las comunidades indígenas como una parte esencial en el desarrollo de la pluriculturalidad colombiana (Constitución Política de Colombia, 1991, arts. $7,8,10,68$, etc.):

Se realizó la entrevista en 2158 hogares, de tal modo que se logró una cobertura global de 91\%. La población estudiada fue de 11522 personas. Para el análisis demográfico, la población se agrupó de la siguiente manera: en la región del Caribe se estudiaron 3040 indígenas de las etnias wayú y arhuaco, en 566 hogares; en la región andina, 4847 indígenas coyaima, paez y emberá (de montaña), en 896 hogares, y en la región amazónica, 3635 indígenas pertenecientes a 16 grupos étnicos (con predominio de los cubeo, desano, tukano y puinave), en 696 hogares. (Piñeros-Petersen y Ruiz-Salguero, 1998)

Los resultados de la encuesta determinaron la distribución mostrada en la figura 1:

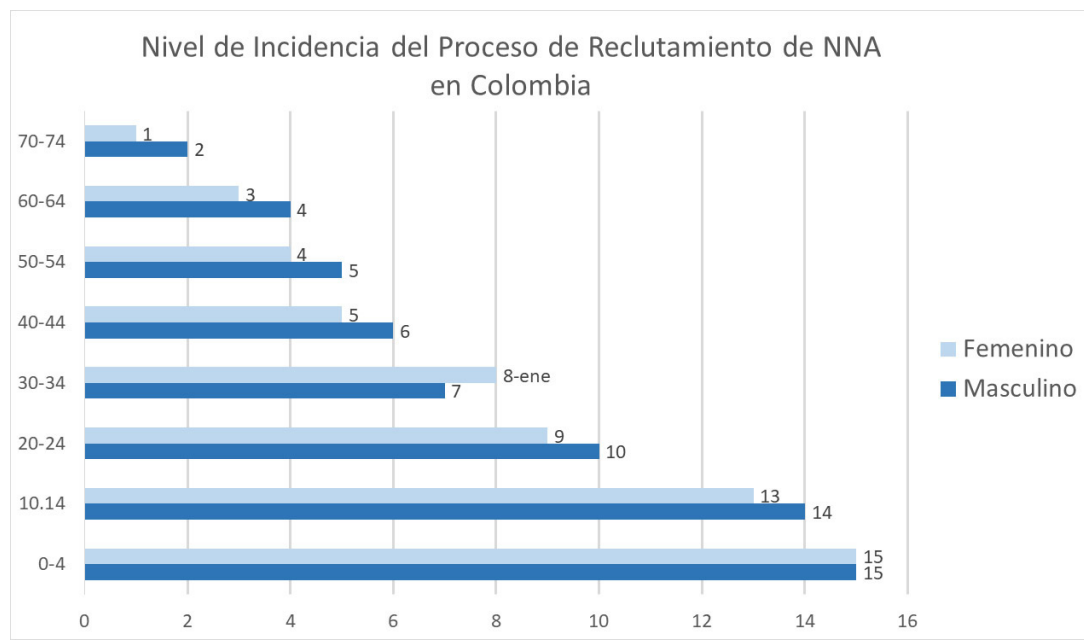

Figura 1. Conocimientos, actitudes y prácticas en la sociedad (1993-1994). Estructura poblacional por edad y sexo.

Fuente: Piñeros-Petersen, M., y Ruiz-Salguero, M. (1998). 
Esta encuesta demuestra que la población indígena, para 1994, conformaba aproximadamente el $34 \%$ de la población nacional. Una referencia muy significativa si se tienen en cuenta las consecuencias en el ámbito poblacional derivadas del conflicto armado interno en los últimos años, el cual ha incidido negativamente en forma directa y particularmente en la población indígena del país.

Por ello, el análisis del marco teórico que trata sobre la reparación integral de víctimas en el posacuerdo en Colombia resulta importante, porque se debe tener un especial cuidado en la planificación de las acciones del Estado para atender unas necesidades que difieren del resto de la población, en particular, por el contexto histórico de exclusión que han sufrido durante toda la historia de Colombia, desde la Colonia e inclusive en la misma República.

\section{Vulneración de los derechos humanos de las comunidades indígenas}

Colombia vivió, por más de cincuenta años, un conflicto armado entre el Estado y la guerrilla de las FARC, uno de los movimientos insurgentes más antiguos y numerosos de América Latina (Ibeas, 1995; Cubides et al., 2019). El conflicto interno armado y su violencia se han convertido en un recurso plenamente utilizado frente a todo tipo de acción o decisión del Estado (Álvarez Calderón y Rodríguez Beltrán, 2018; Žilinčík, 2019); en este campo, siempre se evidenció una lucha y un fortalecimiento de las comunidades indígenas frente a las adversidades que se les presentaban en sus territorios en el marco del conflicto armado.

En el Cauca, por ejemplo, el proceso de descomposición étnico-cultural al cual estaban sometidas las comunidades indígenas no afectó sensiblemente, pues, con ayuda de los diferentes mecanismos de autoridad independiente que reconoce la ley — como resguardos o cabildos (Chakiel y Peysel, 1994)—, se pudo detener parcialmente el daño que podría haber sido ocasionado en contra de muchas comunidades indígenas. Durante toda esta lucha, se podía evidenciar que en las regiones afectadas, se presentaba una grave situación económica que se agudizaba año tras año. Este decremento económico hizo que en la 
población indígena de Popayán hubiera un contraste, en comparación con las poblaciones que se encontraban en las zonas andinas mayoritariamente (PitreRedondo et al., 2017).

En estas últimas, por el contrario, se evidenciaron carencias en la prestación de servicios públicos (alcantarillado, electricidad y pavimentación, entre otras) y en el acceso a la educación o a la salud, con lo cual se ejecutaba una especie de suplicio (Foucault, 1975) para las comunidades indígenas, pues estas adversidades tampoco permitían el avance sociocultural óptimo que se pretendía garantizar con la Constitución Política de 1991 (Pancho, 2007):

Solo basta saber que un derecho se garantiza, se hace sentir y se hace conocer por el Estado, sin necesidad de que el individuo o ciudadano lo conozca mediante la procura del derecho a la salud, es decir, no es admisible que un ciudadano siempre tenga que poseer conocimiento ontológico y técnico para la garantía del derecho. (Rocha-Buelvas, 2012)

Esta pequeña abstracción muestra muchas cosas, desde la obligación estatal de brindar la buena repartición y el buen ejercicio de los DD. HH. reconocidos también en la Constitución Política de Colombia de 1991, hasta los sujetos que generan daños a las comunidades indígenas y las someten frente a un Estado que no reconoce su etnografía ni lleva a cabo las acciones para protegerlas. Vale la pena anotar que autores como Jimeno et al. (2011) trabajan este enfoque, en el que se centran en reconocer el punto de vista subalterno e ir más allá de su registro textual hasta una modalidad de acción conjunta.

La perpetración de injusticias y la usurpación de los territorios de las comunidades indígenas son factores esenciales que se deben contemplar en la búsqueda de una reparación integral, con el fin de localizar un nuevo inicio y una nueva manera de contemplar a estas comunidades, de acuerdo con los principios de protección y respeto establecidos en la Constitución.

Los impactos de la guerra para los pueblos indígenas son variables y, sin dejar de lado el contexto demográfico de la consistencia territorial de estos, es alarmante y dramático observar el índice de homicidios políticos que, entre el 2000 y el 2004, supera la tasa nacional tres veces (Cepeda, 2006), la cual, de por sí, es una de las más altas del mundo. Esto evidencia que los crímenes contra las comunidades indígenas conllevan un proceso de vulneración y desestimación de los DD. HH. de estas comunidades. Como afirma Bello: 
Sus territorios ancestrales atraen hoy las miradas rapaces de los intereses multinacionales y nacionales, que ven en sus tierras riquezas minerales y naturales, o ventajas geoestratégicas; las comunidades son disputadas como bases de apoyo y conocen al Estado no por su presencia social, sino represiva acción. (2003, p. 2)

Además del abandono por parte del Estado y de ser objeto de intereses nacionales económicos y no sociales, estas comunidades estarán subordinadas a intereses internacionales, que van detrás de las riquezas de sus territorios con estrategias maquiavélicas, hasta dejarlos rezagados en el olvido de una sociedad que siempre los hizo invisibles (Merteens, 2016). Estos fenómenos se dan gracias a una limitada regulación estatal ante estos delitos, como el despojo forzado bajo amenazas de muerte, que los llena de inseguridad ${ }^{6}$, miedo ${ }^{7}$, temor y opresión, sin la posibilidad de acudir al amparo del Estado y sin el impulso institucional suficiente para proteger la diversificación cultural (Quintero Cordero, 2020). Estas comunidades, hoy en día, tienen que ser reparadas por todos los daños que han venido sufriendo y que aún siguen afectándolos.

Este fenómeno está arraigado en el hecho colonial que puso a los pueblos originarios en una condición de subordinación política, de explotación económica y de subvaloración cultural (Fajardo, 2004). Esta condición sigue vigente mediante prácticas como la tortura (Sierra-Zamora y Jiménez-Barrera, 2019), la esclavitud, el homicidio y la desaparición forzada, desencadenadas por el tipo de conflicto interno que vive Colombia.

Se puede decir que la sublevación de los grupos indígenas es en defensa propia, en busca de mecanismos que la ley no les ha brindado y, por consiguiente, se puede resaltar la creación de algunos grupos armados indígenas (como lo fue el Quintín Lame), cuyo fin era defenderse del conflicto interno armado que ya les precedía. Sandoval y Capera (2018) subrayan la lucha de la pluriculturalidad indígena :

La experiencia del proceso político liderado por los pueblos indígenas, en los últimos años, tiene como fundamento generar una serie de cambios sustanciales en la esfera institucional de lo público, es decir, una forma de descolo-

6 Según Carrión-Mena (2007), la inseguridad es la dimensión que hace referencia a los hechos concretos de violencia objetiva que generan esa sensación de constante intranquilidad.

7 Aristóteles definía el miedo como una de las emociones más primitivas del ser humano, producida en la psyche y comprendida bajo el concepto de phóbos (Domínguez-García, 2003). 
nizar las estructuras rígidas del poder. Un reflejo concreto de esta situación lo encontramos en la acción de los gobiernos indígenas que ponen en juicio todo tipo de mecanismos constitucionales, reformismos institucionales y acuerdos políticos existentes en los gobiernos de turno en América Latina. (p. 153)

La sublevación indígena, por tanto, espera tener consecuencias en un cambio estructural de política, ley o poder. Lo ideal sería proporcionar nuevas estructuras de participación de los regímenes que gobiernan a estas comunidades y sus territorios, pero también se puede entender como un mecanismo de protección de ellos mismos.

La vulneración de los DD. HH. (Sierra-Zamora y Cubides-Cárdenas, 2018) de las comunidades indígenas se arraiga en una posición de subordinación que siempre ha estado presente para estas. Se destaca, además, el abandono del Estado, lo cual les da pie a los grupos armados para infligirles un daño irremediable mediante homicidios (factor primario de vulneración de los derechos humanos), desapariciones, despojo de tierras y desplazamiento forzado. Finalmente, se evidencia que los orígenes de la sublevación potencial de los indígenas se debe a estas mismas atrocidades cometidas contra de ellos.

\section{El Acuerdo Final para la Paz y la condición vulnerable de las comunidades indígenas}

En este punto es oportuno empezar a tratar el tema de la reparación integral. Según la Comisión Nacional de Reparación y Reconciliación, esta "consiste en dignificar a las víctimas con medidas que alivien su sufrimiento, compensen las pérdidas sociales, morales y materiales que han sufrido y restituyan sus derechos ciudadanos" (Rettberg, 2012). Dicho esto, se puede iniciar el análisis correspondiente a la posición de las comunidades indígenas frente a esta acción determinante de la restitución de sus DD. HH.

En el centro de la visión de la paz del Gobierno hay una preocupación por el territorio, y una preocupación por los derechos. "Derechos" en el sentido en que el proceso de paz necesariamente debe satisfacer los derechos de las víctimas, comenzando por la medida más efectiva de protección y no repetición: poner fin al conflicto. Pero también en el sentido más amplio de garan- 
tizar por igual los derechos constitucionales de los colombianos en todo el territorio. (Jaramillo, 2014)

En este apartado del alto comisionado para la paz se implementa una nueva propuesta y percepción de las preocupaciones que se tratan al final de acuerdo. Con este mismo fin, se dice que la garantía de DD. HH. deberá primar entre cualquier otra disposición en cuanto a la reparación integral de víctimas.

Frente a las primeras relaciones entre el Estado y la organización normativa y de protección de las comunidades indígenas, se puede resaltar el reconocimiento dado en las diferentes constituciones de algunos países de Latinoamérica, por ejemplo, Colombia en 1991, Perú en 1993, Bolivia en 1994 y Ecuador en 1998 (Yrigoyen, 1999). Cada una de estas le brindó cierto apoyo a las comunidades indígenas reconociendo y ejerciendo en materia de la pluriculturalidad y la incorporación de mecanismos de protección: el Estado reconoce y protege la diversidad étnica y cultural de la nación colombiana en el artículo 7 de la Constitución Política de 1991.

En el ámbito que corresponde a la posición de las comunidades indígenas en el acuerdo de paz, este es el contexto:

Subrayando que el nuevo Acuerdo Final presta especial atención a los derechos fundamentales de las mujeres, de los grupos sociales vulnerables como son los pueblos indígenas, las niñas, niños y adolescentes, las comunidades afrodescendientes y otros grupos étnicamente diferenciados. (Oficina del Alto Comisionado para la Paz, 2016, p. 3)

Dicho esto, se puede empezar a desglosar cómo se quiere remediar esta situación en el país. Cabe aclarar, no obstante, que pasados tres años y a pesar de los diferentes esfuerzos por parte del Estado para garantizar la reparación integral a las víctimas de violaciones a los DD. $\mathrm{HH}$. como parte de una política social gubernamental (Cáceres-Mendoza, 2013), la realidad permite sostener que aún quedan tareas pendientes por cubrir bajo este criterio de reparación, entre ellas, la equidad para las mujeres, las comunidades afro y las comunidades indígenas (Sandoval, 2013). En estas últimas conviene detenerse, verificar la posición que les fue establecida en el Acuerdo Final para la Paz y retomar las perspectivas que en él se planteaban respecto a la reparación integral de víctimas indígenas. 
A partir de este acuerdo, se mostrarán los aspectos y las posiciones de las diferentes víctimas, siendo de primordial atención los pueblos indígenas. Se podrán constatar diferentes apartados en los cuales se manifiesta la reparación integral, el restablecimiento de derechos, la repartición de tierras, la satisfacción de necesidades ciudadanas y otros:

Que a la transformación estructural del campo y en particular al cierre de la frontera agrícola, contribuyen campesinos, comunidades indígenas, negras, afrodescendientes, raizales... con un ordenamiento socioambiental sostenible. Para ello es necesario el reconocimiento y apoyo a las Zonas de Reserva Campesina (ZRC) y demás formas de asociatividad solidaria. (Oficina del Alto Comisionado para la Paz, 2016, p. 11)

En esta primera designación es notable el reconocimiento de territorios exclusivos para los pueblos indígenas y de los demás nombramientos territoriales. Este es un punto esencial respecto a la posición de estas comunidades en el acuerdo, pues también se nombran y reconocen las formas de asociación solidaria que generan propuestas de apoyo entre las mismas comunidades y otros estamentos (Cortés et al., 2017).

Bienestar y buen vivir: el objetivo final es la erradicación de la pobreza y la satisfacción plena de las necesidades de la ciudadanía de las zonas rurales, de manera que se logre en el menor plazo posible que los campesinos y las comunidades, incluidas las afrodescendientes e indígenas, ejerzan plenamente sus derechos y se alcance la convergencia entre calidad de vida urbana y la calidad de vida rural, respetando el enfoque de género y la diversidad étnica y cultural de las comunidades. (Oficina del Alto Comisionado para la Paz, 2016, p. 12)

Retomando este literal, se contempla que se trata de la garantía del restablecimiento de derechos de las comunidades indígenas y demás nombradas en el acuerdo, de igual manera se trata del respeto hacia la pluriculturalidad de estas.

Creará mecanismos de concertación y diálogo social entre el Gobierno Nacional, regional y local, los campesinos, comunidades indígenas... y empresas del sector privado que adelanten su actividad económica en los territorios rurales, con el fin de generar espacios formales de interlocución entre actores con diversos intereses, que permitan impulsar una agenda de desarrollo común, orientada hacia la sostenibilidad socio-ambiental, el bienestar 
de los pobladores rurales y el crecimiento económico con equidad. (Oficina del Alto Comisionado para la Paz, 2016, p. 18)

En este apartado se evidencia una propensión hacia el desarrollo y la sostenibilidad económica entre el Estado, las empresas privadas, los pueblos indígenas y las demás partes nombradas, con el fin de establecer una agenda común donde se pacte el bienestar de los pobladores rurales y la equidad del crecimiento de la economía.

El Estado deberá consultar con los pueblos indígenas la forma y la oportunidad en que las decisiones adoptadas o por adoptar por sus respectivas jurisdicciones, respecto de conductas de objeto del presente componente de Justicia, pasarán a ser competencia de este. (Oficina del Alto Comisionado para la Paz, 2016, pp. 170-171)

Con esto se quiere decir que las decisiones que le incumben a las jurisdicciones especiales deberán ser tratadas no solo por el Estado, sino en conjunto, y aplicadas por un progreso en la comunicación entre los pueblos indígenas, su jurisdicción especial y demás entes del Estado que formulen normativas al respecto.

El desarrollo de la economía campesina y familiar... y de formas propias de producción de las comunidades indígenas, negras, raizales... mediante el acceso integral a la tierra y a bienes y servicios productivos y sociales. Los PDET (planes de enfoque territorial) intervendrán con igual énfasis en los espacios interétnicos e interculturales para que avancen efectivamente hacia el desarrollo y la convivencia armónica. (Oficina del Alto Comisionado para la Paz, 2016, p. 21)

En este punto se retoma el nombramiento de la economía como un eje plural entre las comunidades indígenas y las demás nombradas, y esto se relaciona con los PDET, que intervienen en los espacios interculturales como mecanismo efectivo de desarrollo y convivencia armónica entre las partes.

Medidas que buscan asegurar la reparación integral de las víctimas, incluyendo los derechos a la restitución, la indemnización, la rehabilitación, la satisfacción y la no repetición; y la reparación colectiva de los territorios, las poblaciones y los colectivos más afectados por el conflicto y más vulnerables, en el marco de la implementación de los demás acuerdos. Con este fin, se fortalecerán 
los mecanismos existentes, se adoptarán nuevas medidas, y se promoverá el compromiso de todos con la reparación del daño causado. (Oficina del Alto Comisionado para la Paz, 2016, p. 130)

Como parte última de este punto, se reconocen medidas que aseguren la reparación integral e inclusión de otros derechos en los territorios de las poblaciones más vulnerables como las comunidades indígenas. Una vez realizado este ejercicio, de ubicar los apartados en los que se alude a la reparación para las comunidades indígenas en el Acuerdo Final de Paz, se puede inferir que los planteamientos del Estado son consecuentes con la intención de reparar a las víctimas de las violaciones a los DD.HH. en los aspectos de desarrollo de la economía cultural, otorgación y devolución de tierras y el control de medidas que garanticen la consecución de estos resultados.

Para definir este punto, se puede contemplar una garantía de cumplimiento por parte del Estado frente a los diferentes grupos, comunidades, personas y empresas a las que se les debe la reparación integral por ser víctimas del conflicto armado o de sus daños colaterales. Se resalta que a las comunidades indígenas, como población vulnerable, se les ha prometido la devolución de territorios y una protección especial para estos, una economía que se desarrolla en lo rural y otros mecanismos garantes del impulso económico entre pueblos y otras personas también víctimas del conflicto (López et al., 2016).

\section{La reparación integral para las comunidades indígenas de cara al posacuerdo}

Conviene verificar ahora si los diferentes tratados y posiciones dadas a las comunidades indígenas en el Acuerdo Final de Paz han sido constituidos de forma consecuente con el objetivo de llevar a cabo una reparación integral de las víctimas. Para ello es necesario saber que la negociación entre las guerrillas y el Estado colombiano no ha de conducir a un escenario de posconflicto, sino de posacuerdo, porque los conflictos sociales no tienden a desaparecer, sino que se van a trabajar y gestionar por medios no violentos (Molina, 2017).

Un escenario de paz requiere de una construcción adicional, que va más allá de la ausencia del conflicto. Este proceso de ajuste, reconciliación, revalo- 
ración humanista y reencuentro del proyecto nacional no puede ser una paz incompleta. Por esta razón, el uso de una terminología como posacuerdo es lo adecuado, mientras la nación se intenta aproximarse a la reparación integral de víctimas del conflicto, generando espacios convenientes para la vida en armonía y paz.

Una vez aclarado este concepto de posacuerdo, es necesario establecer diferentes puntos de referencia en cuanto a lo trabajado en el Acuerdo Final de Paz (Moreno, 2017), con el fin de identificar los qué se ha cumplido, qué se está gestionando y qué se está ignorando.

Primeramente, cabe resaltar las opiniones de las comunidades indígenas y de otros grupos mencionados en el Acuerdo Final de Paz en cuanto a las situaciones que se presentan frente a los pactos tratados en dicho documento:

A partir de un ejercicio de investigación cualitativa realizado en el municipio de San Carlos, Antioquia respecto a los significados que las comunidades han construido en torno al proceso de paz entre el Gobierno y las FARC, se encuentra que los/as participantes consideran que la paz ha sido capturada por el Estado, los medios de comunicación y algunos sectores económicos en pro del desarrollo extractivista (minero-energético), configurando una paz que se construye desde arriba, que es manipulada, que no obedece a los intereses de los/as campesinos y víctimas, que no logra transformar las condiciones estructurales que están a la base de la emergencia del conflicto armado y que no posibilita la participación activa y real de la ciudadanía. (Barrera Machado et al., 2018)

Se trata de una primera impresión negativa de la población en cuanto al Acuerdo. Se denota que, en esta investigación, los pobladores de la región, entre ellos, las comunidades indígenas, manifiestan que el Estado ha decidido etiquetar una paz que está siendo constituida desde "arriba”. Esto quiere decir que se ve como una tergiversación de los fondos, los recursos, los implementos y los mecanismos que habían sido tratados en el Acuerdo:

A nivel psicosocial, dicha captura ha dado lugar a la construcción de una orientación emocional colectiva de desconfianza e indignación frente al proceso de paz, la cual se erige en instrumentos de control en el plano político, ya que desactiva la acción colectiva, promueve la desesperanza, el fatalismo y la apatía de la ciudadanía. (Barrera Machado et al., 2018) 
Retomado este artículo, se evidencia que esto también conlleva diversos fallos y vacíos que se pueden llegar a expresar al momento de iniciar la reparación integral de víctimas, en especial de las comunidades indígenas: faltas en la redistribución de tierras o en la nueva formación de mecanismos de comunicación entre las jurisdicciones que deben de estar entrelazadas con el Estado (Lozano-Acosta, 2010; Giraldo Chaparro, 2019), además de otras inconsistencias que puede llegar a ocasionar este tipo de percepciones o de evidencias frente al Acuerdo.

Sin embargo, los pueblos indígenas y las autoridades deben valorar los aspectos mencionados en aras de superar limitaciones y dificultades ante diferentes ejercicios de reasignación de derechos (Güejía Campo, 2017) o con el fin de reencontrar estrategias para la justa repartición de territorios según lo amparado por la Constitución Política de Colombia y el Acuerdo.

De igual manera, se considera, que la restitución de tierras y la otorgación de nuevos mecanismos de defensa es la solución principal y el aspecto fundamental de la reparación integral de víctimas indígenas y afrocolombianas (Serna, 2017). Es requisito, por tanto, establecer los modelos en los cuales se han ido determinando los nuevos territorios y los mecanismos de protección de las comunidades indígenas. Existen algunos encuentros estratégicos en el tema de tierras en distintos sectores de la sociedad, los cuales confluyen en el tema específico de la restitución (Uprimny-Yepes y Sánchez, 2010), pero siguen existiendo desacuerdos sobre el tema.

Por un lado, están quienes abogan por una política de restitución que se concentre en corregir la ilegalidad del despojo y aclarar los títulos y los derechos individuales sobre los bienes (Gómez y Prada, 2013). Esto serviría para satisfacer un punto de la reparación integral: el que concierne al desarrollo de la economía, pues se dinamiza el mercado de tierras y se da pie al desarrollo rural que permita modernizar la producción agraria en beneficio de todas las partes incluidas y mencionadas en este punto del Acuerdo.

Por otro lado están los defensores de la adopción de una política de restitución que satisfaga no solo los objetivos de una "justicia correctiva" (Kalmanovitz, 2010), sino de reconocimiento y redistribución a favor del campesinado y las comunidades étnicas. De igual manera, este tipo de defensores promovería una 
mejora integral en lo que concierne a la paz territorial y la reparación respecto de los DD. HH. violentados de las comunidades indígenas.

Otro punto a tratar se deriva de la reparación de derechos y la oportunidad de generar espacios de paz en los territorios de las comunidades indígenas (Rodríguez, 2014), territorios que deben constituirse en la realidad social del posacuerdo, donde procesos como los de la guardia indígena ${ }^{8}$ asuman un papel de intermediario en este escenario, para regular sus dinámicas sociales y garantizar una paz territorial.

Esto demuestra un avance significativo frente a la posición del Estado y su promesa de reparación integral de víctimas frente al aspecto de la paz territorial de la población indígena, donde estas comunidades también optaron por asumir un nuevo rol y una nueva posición con respecto a los escenarios que el Estado se comprometió a proteger.

Detalle especial, separado y complementario es el elemento patrimonial que implica toda acción del Estado en la tutela de los derechos de las poblaciones indígenas, en particular, porque estas están vinculadas de forma especial a los siguientes aspectos:

a. Muchas de las zonas que les pertenecen tradicionalmente cuentan con riquezas naturales, como hidrocarburos, minerales y recursos biológicos significativos que, en esencia, les pertenecen al Estado, pero cuya explotación no puede pasar por encima del desarrollo de las comunidades indígenas, ya que toda actividad en dichos territorios implica la ejecución de actividades propias de una consulta previa (Bermúdez-Tapia, 2011).

b. Las zonas y territorios indígenas pueden ser materia de procedimientos de registro de propiedad inmueble y ello permite su comercialización en el ámbito ordinario, lo que da lugar a condiciones altamente negativas para la sostenibilidad social, cultural y territorial de las comunidades nativas.

8 Se mencionó anteriormente la sublevación de las comunidades indígenas dando pie a la generación de guardias indígenas que tenían como objetivo, defender sus tierras y derechos en el conflicto armado. 
c. Las poblaciones indígenas se ven condicionadas a un nivel de pobreza extremo, por lo cual se ven sometidas a recurrir a acciones que atentan contra sus propios intereses al ser forzadas a ejecutar operaciones financieras, económicas o bancarias que se sostienen sobre la base del patrimonio inmaterial que les pertenece.

Estos elementos son expuestos objetivamente en el ámbito judicial, por cuanto la misma accesibilidad a derechos ordinarios - como el debido proceso, la tutela judicial efectiva o el derecho a la defensa - se ve limitada por las limitaciones impuestas por el uso de idiomas vernáculos distintos al español en la administración pública, tal como sucede en Perú, Paraguay, Bolivia o Ecuador (Bermúdez-Tapia, 2011).

\section{La justicia transicional como medio para la reparación integral de víctimas}

Para continuar desglosando cómo se ha ido estableciendo la reparación integral en el posacuerdo, es necesario conocer un término bastante apropiado y utilizado a lo largo de todo el desarrollo, tanto del acuerdo como de la reparación: la justicia transicional.

La justicia transicional puede ser entendida como la concepción de justicia asociada con periodos de cambio político, caracterizados por respuestas legales que tienen el objetivo de enfrentar los crímenes cometidos por regímenes represores anteriores (Teitel, 2003). Teniendo en cuenta esta definición, conviene determinar la actuación de la justicia transicional en el posacuerdo, puesto que el discurso está dirigido a preservar un Estado de derecho identificado principalmente con la conservación de la paz (Villa y Joinet, 2008).

Puesto que la finalidad de la reparación integral de víctimas es conllevar la completa estimulación de la paz a nivel nacional, el objetivo de la justicia transicional es facilitar la preservación de esta y generar estrategias que conlleven el mismo fin. En otra palabras, la justicia transicional es un mecanismo fundamental de paz que se desarrolla ante cambios políticos importantes y que está acompañado de nuevas legislaciones orientadas a cumplir dicho objetivo. 
Una característica primordial de la justicia transicional es que, a diferencia de la justicia ordinaria, no promueve actos de retribución o actos punitivos, sino que simplemente se enfoca y encuentra paz en actos de reparación y restauración (Ferrajoli, 2016). Por esta razón, es el mecanismo óptimo para el posacuerdo y la transición hacia la paz, es el requerimiento adecuado para finiquitar la relación de la reparación integral de víctimas y el Acuerdo Final para la Paz. El eje fundamental, además, es reversión de daños a los DD. HH. $\mathrm{y}$ a otros problemas a los que fueron sometidos las comunidades indígenas.

\section{Restitución de tierras como factor fundamental de la reparación integral de víctimas}

La Ley 1448 de 2011 (Ley de Víctimas y Restitución de Tierras) busca establecer un conjunto de medidas de atención y asistencia que permita ofrecer las garantías necesarias para la reparación integral del dolor que han sufrido quienes han sido víctimas del conflicto armado, prolongado por más de sesenta ańos (Gaviria y Yimi, 2016). Es importante tener presente que estas víctimas han tenido que desprenderse de sus predios por el abandono, el despojo o el desplazamiento forzado, y que buscan en la restitución de tierras los mecanismos necesarios para la dignificación de su persona, la inclusión social y la protección del Estado respecto a las garantías de no repetición (es decir, no tener que volver a abandonar sus tierras), para llegar, así, al disfrute pleno y sostenible de sus DD. HH., vulnerados por las diferentes acciones bélicas del conflicto.

Para garantizar el retorno de las comunidades indígenas, campesinos y familias a sus territorios, la Ley 1448 establece medidas de protección personal, orientadas a preservar la vida del reclamante que ha sido víctima de la hostilidad del conflicto y al saneamiento jurídico respecto a su relación con el predio (Marulanda y Moya, 2012). Esto último, porque existen reclamantes no indígenas que quieren proclamarse como poseedores y propietarios de estos terrenos jurídicamente.

Hasta ahora, los actos de despojo han sido identificados como compraventas forzosas, escrituras de englobe de terrenos agrandados por efecto del 
desplazamiento abusivo de cercas, resoluciones de adjudicación de baldíos expedidas por el Estado sin el cumplimiento cabal de los requisitos legales y posesión por usurpación directa (Reina, 2014). Esto demuestra que durante la etapa del conflicto armado en Colombia los territorios de las comunidades indígenas y demás merecedores de reparación mencionados en el Acuerdo fueron, en su mayoría, forzados al despojo o a vender a injustos precios sus inmuebles, bajo amenaza de muerte.

Ahora bien, se debe considerar que la reparación integral de víctimas deberá retomar el planteamiento de la Ley 1448 de 2001 en cuanto a la retribución de nuevos territorios a las comunidades indígenas, con el fin de cumplir lo tratado en el Acuerdo Final de Paz — que, en el fondo, es lo mismo establecido en la Constitución Política de Colombia de 1991—. Para el aspecto de la otorgación de nuevos territorios, se deberá prever cierto tipo de reflexiones debido a la complejidad del fenómeno social trabajado, que implica acudir a conceptos que involucran distintos campos del conocimiento, entre los que cabe resaltar el campo jurídico, sociológico, psicológico y político (Bustamante, 2015).

\section{Conclusiones}

A partir del estudio desarrollado a lo largo de este capítulo, se pueden destacar varios ítems esenciales para entender el funcionamiento de la reparación integral de víctimas indígenas en el contexto del posacuerdo en Colombia:

- La reparación integral como mecanismo de dignificación de las víctimas del conflicto mediante el alivio al sufrimiento de estas.

- $\quad$ El Acuerdo, que es el objeto de estudio, constituye la base del desarrollo de la Reparación, puesto que en él se manifiesta expresamente que las comunidades indígenas son merecedoras de reparación.

- La vulneración de los DD. HH., como concepto, hace referencia a las situaciones indignas que las comunidades indígenas tuvieron que soportar durante todo el conflicto armado: homicidios, torturas, temor y pobreza, entre muchísimas otras vulneraciones que ocurrieron en esta etapa. 
Se concluye, entonces, que las comunidades indígenas son objeto legítimo de reparación integral, que estas han entrado a ser parte fundamental del complejo de víctimas con respecto a las cuales el Acuerdo indica la necesidad de resarcimiento, reparación y devolución de derechos esenciales, de territorios e indemnizaciones.

También cabe resaltar que el Acuerdo está otorgando territorios, mientras que el Estado se está encargando de remediar y proponer estrategias que conlleven la reparación completa y a la devolución efectiva de los territorios de los que fueron despojadas las comunidades indígenas. Además, el Estado está haciendo eficientes los mecanismos de protección territorial contemplados en la Constitución de 1991, como los cabildos o los resguardos, para que las denominadas guardias indígenas perciban el nuevo escenario de tranquilidad, paz y no repetición que el posacuerdo plantea. Por otra parte, la comunicación entre el Estado y las comunidades indígenas es posible debido al mejoramiento de las condiciones sociales y culturales de las primeras gracias a las nuevas disposiciones políticas.

Así mismo, se destaca que la reparación integral de los DD. HH. inicia en el momento mismo en que estas etnias fueron nombradas y reconocidas como comunidades vulnerables, merecedoras de cuidado y atención especial. Esto les da la posibilidad de hacer parte de la restauración de bienes, servicios y otras prestaciones públicas de las que antes carecían, mientras se resarce y detiene el daño del conflicto, en especial, el desplazamiento forzado y, con ello, la disminución notable del índice de homicidios.

Por último, se resalta que la población indígena colombiana ha variado su estructura desde 1994, con la creación de las nuevas responsabilidades estatales frente a ellas y con el reconocimiento sociopolítico adecuado hoy en día. Gracias a lo anterior, se ha logrado que las comunidades indígenas sean parte integral de la sociedad colombiana, puesto que son tenidas en cuenta y participan de los aspectos de la vida cotidiana de las ciudades o departamentos, espacios que antes tenían prácticamente vetados.

Esto ayuda a responder el interrogante que se planteaba al inicio del capítulo: ¿Cuál ha sido la reparación integral de las comunidades indígenas en el posacuerdo colombiano? La clara respuesta es que las comunidades indígenas han entrado en el Acuerdo y han sido reparadas de manera integral en la mayoría de los aspectos mencionados. 


\section{Referencias}

Álvarez Calderón, C. y Rodríguez Beltrán, C. (2018). Ecosistemas criminales. Revista Cientifica General José María Córdova, 16(24), 1-30. https://doi.org/10.21830/19006586.352

Barrera Machado, D., Villa Gómez, J. D., y Insuasty Rodríguez, A. (2018). Significados construidos en torno a la paz por comunidades residentes en el municipio de San Carlos, Antioquia: efectos psicosociales de la captura de la paz. Kavilando, 10(1), 53-77.

Bello, M. (2003). El desplazamiento forzado en Colombia: acumulación de capital y exclusión social. Programa Andino de Derechos Humanos; Universidad Andina Simón Bolívar.

Bermúdez-Tapia, M. (2011). Los derechos lingüisticos. Ediciones Legales.

Bermúdez-Tapia, M. (2017). Análisis del manejo del desarrollo legislativo y temático de la consulta a pueblos indígenas. Revista de Análisis Especializado en Jurisprudencia, 39(4). 27-404

Bustamante, V. L. (2015). Lineamientos de política pública a partir de la doble incidencia entre la ley 1448 de 2001 y los sobrevivientes del desplazamiento forzado. Revista Eleuthera, 12, 162-177.

Cáceres-Mendoza, E. (2013). Justicia transicional y derecho a la reparación integral. Aproximación al caso colombiano. Novum Jus: Revista Especializada en Sociología Jurídica y Politica, 7(2), 55-87. https://doi.org/10.14718/NOVUMJUS.2013.7.2.2

Carrión-Mena, F. (2007). Percepción inseguridad ciudadana. Flacso.

Cepeda, I. (2006). Genocidio político: el caso de la Unión Patriótica en Colombia. Revista Cetil, 1(2), 101-112.

Chackiel, J., y Peyser, A. (1994). La población indígena en los censos de América Latina. Repositorio Digital Cepal. https://repositorio.cepal.org/handle/11362/12491

Cortés Sánchez, E. M., Cova Villanueva, M., Forer, A., Busintana, K., y Ramírez Hernández, H. F. (2017). Proceso de justicia y paz. Evaluación y aportes en casos de pueblos indígenas. Editorial Educosta.

Cubides-Cárdenas, J., y Sierra-Zamora, P. (2018). Reparación integral de las víctimas en la justicia transicional: historia, debate y actualidad dentro del acuerdo de paz firmado por el gobierno de Colombia y las FARC-EP. En E. A. Velandia Canosa (Ed.), Derecho procesal constitucional. Universidad La Gran Colombia.

Cubides Cárdenas, J. A., Sierra Zamora, P. A., Calixto Ortiz, D. A., y Pabón Caballero, N. (2019). Terrorismo por parte de las FARC-EP y políticas públicas orientadas a la seguridad nacional en Colombia durante 1990-2000. Revista Cientifica General José María Córdova, 17(26), 309-325. https://doi.org/10.21830/19006586.404

D’Angelo, A. (2017). Restituir las tierras en el marco del postconflicto colombiano: una mirada al caso indígena Wiwa de la Sierra Nevada de Santa Marta. Periferia: Revista de Recerca $i$ Formació en Antropologia, 22(2), 112-135. https://doi.org/10.5565/rev/periferia.618

Domínguez García, V. J. (2003). El miedo en Aristóteles. Psicothema, 15(4), 633-666.

Fajardo, R. Y. (2004). Pluralismo jurídico, derecho indígena y jurisdicción especial en los países andinos. El Otro Derecho, 30, 171-195. 
Ferrajoli, L. (2016). La justicia penal transicional para la Colombia del postconflicto y las garantías para la paz internacional. Crítica Penal y Poder, 10, 146-161.

Foucault, M. (1975). Vigilar y castigar: nacimiento de la prisión. Editorial Siglo XXI.

Garay Acevedo, C. P., y Pérez Guecha, A. del P. (2018). Los derechos humanos en Colombia. Revista Cientifica General José María Córdova, 16(23), 83-105. https://doi. org/10.21830/19006586.307

Gaviria, D., y Yimi, A. (2016). Ley 1448 de 2011. Análisis crítico a la restitución de tierras como mecanismo de reparación integral. Universidad Católica de Colombia.

Giraldo Chaparro, F. R. (2019). Las Fuerzas Militares como instrumento de socialización del Estado. Revista Cientifica General José María Córdova, 17(28), 939-970. https://doi. org/10.21830/19006586.517

Gómez, R. S., y Prada, M. A. (2013). Reflexiones en torno a la aplicación de la Ley 1448 de 2011 y la restitución de tierras en Colombia. Revista de la Facultad de Derecho y Ciencias Politicas, 43(119), 533-566.

Güejía Campo, J. D. (2017). Proyecciones y apuestas politicas de la Guardia Indígena Nasa del Resguardo de Tacueyó, municipio de Toribio, Cauca, frente al escenario de Posacuerdo (20162017) [Trabajo de pregrado]. Biblioteca Digital de la Universidad del Valle. http://bibliotecadigital.univalle.edu.co/handle/10893/13241

Ibáńez, A. M., y Querubín, P. (2004). Acceso a tierras y desplazamiento forzado en Colombia. Documento Cede, 23, 1-114.

Ibeas, J. (1995). Génesis y desarrollo de un movimiento armado indígena en Colombia. América Latina Hoy, 10, 37-48.

Jaramillo, S. (2014). La paz territorial. Interaktive-Demokratie.org. http://bit.ly/2S7jW4W

Jimeno, M., Varela, D., y Castillo, Á. (2011). Experiencias de violencia: etnografía y recomposición social en Colombia. Sociedade e Cultura, 14(2), 275-285. https://doi.org/10.5216/ sec.v14i2.17604

Kalmanovitz, P. (2010). Justicia correctiva vs. justicia social en casos de conflicto armado. Estudios Socio-Jurídicos, 12(2), 59-85.

Laurent, V. (1997). Población indígena y participación política en Colombia: las elecciones de 1994. Análisis Político, 31, 63-81.

López, W., Andrade, A. F, y Correa-Chica, A. (2016). El proceso de pedir perdón como condición necesaria para la construcción de paz en medio del conflicto armado en Colombia. Revista Argentina de Clínica Psicológica, 25(2), 187-194.

Lozano-Acosta, C. H. (2010). El daño ambiental en los programas de reparación colectiva para comunidades indígenas y afrodescendientes afectadas por el conflicto armado en Colombia. International Law: Revista Colombiana de Derecho Internacional, 8(17), 287-322.

Marulanda, M., y Moya, A. (2012). Reparación transformadora, retorno y restitución de tierras: apuntes sobre el artículo 101 de la ley 1448 de 2011. Revista de Derecho Público, 29, 4-38. http://dx.doi.org/10.15425/redepub.29.2012.01

Meertens, D. (2016). Justicia de género y tierras en Colombia: desafíos para la era del posacuerdo. European Review of Latin American and Caribbean Studies, 102, 89-100. https://doi.org/10.18352/erlacs.10166 
Molina, N. (2017). Retos de la psicología en la construcción de paz en Colombia: ¿̨atalismo o ingenuidad? Pensamiento Psicológico, 15(1), 115-126.

Moreno, J. D. (2017). Paz, memoria y verdad en El Salvador: experiencias y lecciones para la Colombia del posacuerdo. Análisis Politico, 30(90), 175-193.

Oficina del Alto Comisionado para la Paz. (2016). Acuerdo final para la terminación del conflicto y la construcción de una paz estable y duradera. http://www.altocomisionadoparalapaz.gov. co/procesos-y-conversaciones/acuerdo-general/Paginas/inicio.aspx

Pancho, A. (2007). Participación de las mujeres nasa en los procesos de autonomía territorial y educación propia en el Cauca, Colombia. Mujeres indígenas, territorialidad y biodiversidad en el contexto latinoamericano, 53.

Piñeros-Petersen, M., y Ruiz-Salguero, M. (1998). Aspectos demográficos en comunidades indígenas de tres regiones de Colombia. Salud Pública de México, 40, 324-329.

Pitre-Redondo, R., Cardona-Arbeláez, D., y Hernández-Palma, H. (2017). Proyección del emprendimiento indígena como mecanismo de competitividad en el postconflicto colombiano. Revista de Investigación, Desarrollo e Innovación, 7(2), 231-240. https://doi. org/10.19053/20278306.v7.n2.2017.6068

Quintero Cordero, S. P. (2020). Seguridad ciudadana y participación de las comunidades en América Latina. Revista Cientifica General José Maria Córdova, 18(29), 5-24. https://doi. org/10.21830/19006586.561

Reina, J. V. (2014). Análisis comparativo de los diseños institucionales que regulan la participación de las víctimas en Colombia: antes y después de la Ley 1448 de 2012. Estudios Socio-Jurídicos, 16(1), 165-206.

Rettberg, A. (Comp.). (2012). Construcción de paz en Colombia. Ediciones Uniandes.

Rocha-Buelvas, A. (2012). Derecho a la salud en Colombia: la utopía anunciada. Espacio Abierto, 21(1), 59-80.

Rodríguez, G. A. (2014). De la consulta previa al consentimiento libre, previo e informado a pueblos indigenas en Colombia. Editorial Universidad del Rosario.

Sandoval, D. A. (2013). Reparación integral y responsabilidad civil: el concepto de reparación integral y su vigencia en los dańos extrapatrimoniales a la persona como garantía de los derechos de las víctimas. Revista de Derecho Privado, 25, 237-273.

Sandoval, E. A., y Capera, J. J. (2018). El movimiento indígena colombiano y su relación con el giro decolonial en América Latina. Ratio Juris, 13(27), 145-172. https://doi. org/10.24142/raju.v13n27a6

Serna, D. R. (2017). El territorio como víctima. Ontología política y las leyes de víctimas para comunidades indígenas y negras en Colombia. Revista Colombiana de Antropología, 53(2), $85-113$.

Sevilla, M. (2007). Indígenas urbanos y las políticas del reconocimiento dentro del contexto colombiano. Perspectivas Internacionales, 3(1), 7-24.

Sierra-Zamora, P. A. (2018). La tutela de los Derechos Humanos en situaciones de postguerra: el caso colombiano [Documento de trabajo]. https://doi.org/10.17605/OSF.IO/7KM83 
Sierra-Zamora, P. A., y Cubides-Cárdenas, J. A. (2018). Derechos humanos en Colombia: A raiz del conflicto armado con las FARC [Documento de trabajo]. https://doi.org/10.17605/ OSF.IO/CWK56

Sierra-Zamora, P. A., y Jiménez-Barrera, L. V. (2019). Genealogía de la tortura en Colombia: una mirada desde los derechos humanos. Novum Jus, 13(2), 1-14. https://doi.org/10.14718/ NovumJus.2019.13.2.7

Teitel, R. (2003). Genealogía de la justicia transicional. Harvard Human Rights Journal, 16, pp. 69-94.

Uprimny-Yepes, R., y Sánchez, N. C. (2010). Los dilemas de la restitución de tierras en Colombia. Estudios socio-jurídicos, 12(2), 305-342.

Villa, H. V., y Joinet, L. (2008). Introducción a la justicia transicional. Claves de Razón práctica, 180, 76-82.

Villa, W., y Houghton, J. (2005). Violencia politica contra los pueblos indígenas en Colombia 1974-2004. Iwgia.

Yrigoyen, R. (1999). Reconocimiento constitucional del derecho indígena y la jurisdicción especial en los países andinos (Colombia, Perú, Bolivia, Ecuador). Revista Pena y Estado, 4, 1-19.

Žilinčík, S. (2019). La atribución pública como reguladora de emociones. Revista Científica General José María Córdova, 17(28), 869-889. https://doi.org/10.21830/19006586.528 